\title{
FILOSOFÍA Y POLÍTICA DE LIBERACIÓN EN LA OBRA DE ENRIQUE DUSSEL ${ }^{1}$
}

Philosophy and Politics of Liberation in Enrique Dussel's work

\section{PRECIADO CORONADO, Jaime Antonio ${ }^{2}$}

\begin{abstract}
Resumen: La filosofía y política de liberación de Enrique Dussel, supera las filosofías políticas "civilizatorias" de la modernidad occidental. Indaga sus raíces filosóficas y políticas eurocéntricas, que terminaron por subordinar a América Latina, sin reconocer el quiebre epistemológico que significó la invasión de América, al fundar la modernidad como totalidad del sistema mundo. Su pensamiento crítico, como contra-relato, da voz a los olvidados o excluidos, revaloriza saberes múltiples, heterogéneos, donde el poder, o la pluralidad de contrapoderes, tienden a ser negados o acallados, pero resisten y re-sienten la dominación. Dussel, imagina la realidad otramente; aquí se destacan seis tesis: 1) La herencia de Las Casas, Suárez y Vitoria; de la teología política a la modernidad colonial(izada); 2) El análisis desde la exterioridad en el pensamiento eurocéntrico; 3) La contemporaneidad de la filosofía y la política de la liberación; 4) Eurocentrismo y ética liberadora; 5) El pensamiento geopolítico y la modernidad en la política de la liberación; 6) La Transmodernidad en Dussel, que supera la modernidadcolonialidad del Sistema Mundo. En conclusión, la filosofía y la política de la liberación, ofrecen un campo contra hegemónico frente a la modernidad opresora, excluyente, depredadora, patriarcal y colonizadora del poder y del pensamiento.
\end{abstract}

Palabras clave: Filosofía y Política de Liberación. Pensamiento anglo-euro-céntrico. Crítica de la modernidad. Geopolítica del conocimiento. Transmodernidad. América Latina.

\begin{abstract}
The philosophy and politics of liberation of Enrique Dussel, surpasses the "civilizatorial" political philosophies of Western modernity. He explores its philosophical and Eurocentric political roots, which ended up subordinating Latin America, without recognizing the epistemological break that the invasion of America meant, when founding modernity as a whole of the World System. His critical thinking, as counter-narrative, gives voice to the forgotten or excluded, revalues multiple, heterogeneous knowledge, where power, or the plurality of counter-powers, tend to be denied or silenced, but resist and re-feel the domination. Dussel, imagine the reality autrement, where six theses stand out: 1) The inheritance of Las Casas, Suárez and Vitoria; from political theology to colonial modernity; 2) Analysis from the exteriority in Eurocentric thinking; 3) The contemporaneous philosophy and politics of liberation; 4) Euro centrism and liberating ethics; 5) Geopolitical thinking and modernity in the politics of liberation; 6) The Transmodernity in Dussel, that surpasses the modernitycolonialism of the World System. In conclusion, the philosophy and politics of liberation offer an anti-hegemonic front against oppressive, exclusionary, predatory, patriarchal and colonizing power and thought.
\end{abstract}

Keywords: Philosophy and Politics of Liberation. Anglo-euro-centric thinking. Criticism of modernity. Geopolitics of knowledge. Transmodernity. Latin America.

\footnotetext{
${ }^{1}$ Recebido em: 22 mai 2018; Aceito em: 14 ago. 2018.

2 Profesor Investigador del Departamento de Estudios Ibéricos y Latinoamericanos, Coordinador del Doctorado en Ciencia Política, Centro Universitario de Ciencias Sociales y Humanidades, Universidad de Guadalajara, México. Este trabajo es una adaptación del Prólogo que escribe el autor, para el libro: Homenaje a Enrique Dussel, coordinado por Federico Ledesma, próximo a ser publicado por la Universidad de Guadalajara. japreco@hotmail.com
} 
Enrique Dussel compone un relato de la filosofía y política de liberación, sobre nuevas bases que implican superar a las filosofías políticas que se han constituido en las referencias civilizatorias de la modernidad occidental; por una parte, se trata del reconocimiento del helenocentrismo, cuyo origen no griego es paradójico, pues el mundo greco-romano surge de la polémica con la civilización semita sin reconocer esa influencia. Por otra parte, el occidentalismo, no advierte la importancia del mundo bizantino para los inicios de la Modernidad política. En la historia de la política de liberación, emerge con fuerza la historia de los pueblos, que son los actores políticos olvidados, invisibilizados, menospreciados, minimizados. Al reclamar por su reconocimiento, estos actores se configuran desde un pensamiento o desde una filosofía política otra, que exige auto-liberarse del pensamiento dominante que los ha acotado.

Por ello, el proyecto de esa modernidad que da la espalda a la diversidad filosófica y epistemológica del otro y la otra, del diferente, bebe de una sola fuente: el eurocentrismo de las filosofías políticas que obvian, por desprecio o por ignorancia, todo lo alcanzado práctica o políticamente por otras culturas que no parten de los supuestos universales modernos. De acuerdo con una visión de la historia según criterios eurocéntricos, se planteará evacuar las filosofías políticas otras, a las que se consideran inferiores. Sin embargo, el colonialismo teórico que impuso el sistema mundo moderno en los países periféricos, mostró que su imaginario de la modernidad occidental no se había liberado de las ataduras teocráticas y monárquicas que se reproducían en el centro y en la periferia. Enrique Dussel, indaga las raíces filosóficas y políticas del proyecto de la modernidad, que terminaron por subordinar a América Latina dentro del escenario filosófico eurocéntrico. Lejos de reconocer el quiebre epistemológico en el que la conquista, o invasión de América, funda la modernidad como totalidad del sistema mundo.

Desde el pensamiento crítico, esta historia no es un relato más, sino un contrarelato, que da voz a los olvidados o excluidos por las filosofías o historias oficiales, desde una revalorización de saberes múltiples heterogéneos y desde una revalorización del poder, de los contrapoderes en su pluralidad, que tienden a ser negados o acallados, pero que resisten y re-sienten la dominación. La filosofía y política de liberación de Dussel, busca lo no dicho y lo no investigado en lo ya dicho. Tal pensamiento, y la teoría 
que lo sustenta, se elabora desde un lugar donde se enuncia y se imagina la realidad otramente. Se trata de una filosofía de la praxis, para decirlo en términos de Antonio Gramsci, que también se distancia de los metarrelatos de corte eurocéntrico que colonizaron igualmente al marxismo dogmático, esclavizado por la centralidad del proyecto moderno. No obstante el secularismo universalista moderno, que se opone a la teología política tradicional de los regímenes antiguos, la hegemonía civilizatoria que se proponen tanto el capitalismo como el marxismo, terminaron sin comprender las contradicciones que subyacen en la continuidad de la historia como portadora de diversidades y diferencias.

De aquí proviene otra originalidad dusseliana: el concepto de transmodernidad, unidad de la pluriversidad auto reconocida en la diversidad. Ni el paraíso capitalista de la modernidad de los iguales, ni el voluntarismo revolucionario creador de proyectos igualitarios pudieron superar la brecha existente entre proyecto y discurso; la fuerza de sus utopías se fundó sobre la razón -dijera Kant el imperativo categórico de la razón-, y no en el reconocimiento de múltiples voces, razones, decires. En contraste, para Dussel, el «decir» de la corporalidad sufriente de los «condenados de la Tierra», cualquiera que sea el régimen político que los domina, es su punto de partida.

En su obra: Política de la Liberación, Dussel desarrolla tres ideas fuerza que constituyen un proyecto liberador:

1) Una historia mundial y crítica, que ofrece una mirada propia de la larga duración en la que se sedimenta el pensamiento, como saber y poder, como reflexión y acción que se construyen bajo la filosofía política, en consonancia con los tiempos de crisis universal del imaginario que inspira al sistema mundo moderno, siendo los oprimidos de la Tierra el lugar de enunciación desde donde se despliega la política de liberación.

2) Lo que él llama 'arquitectónica' de la filosofía política, hace una descripción de la totalidad política en abstracto, sin entrar todavía en la complejidad concreta, lo cual permitirá mostrar las contradicciones históricas, los conflictos, la crisis y los procesos de pensamiento y acción propiamente creativos que sitúan en su originalidad a la Política de la Liberación. Una idea de lo político que supone la descripción ontológica del poder político, concepto que subestiman o evaden las 
filosofías políticas modernas, pues ciertamente la Modernidad se identificó con la dominación, en tanto 'paradigma' orientador de sentido.

3) La filosofía política contemporánea es eminentemente pragmática en su ataque a problemas específicos de la convivencia humana y su manejo de los conflictos, pero, sin dejar de abordar aspectos trascendentales para esa convivencia, esas filosofías -sean modernas o posmodernas- no enfocan los componentes mínimos y necesarios de la y lo político desde el giro decolonial o de la crítica a la colonialidad del poder -de origen anglo euro céntrico-, como lo proponen en su obra Aníbal Quijano y Enrique Dussel. Lo cual interroga sobre un posible y renovado concepto del poder a partir de las recientes experiencias políticas latinoamericanas -impulsadas por intuiciones colectivas innovadoras-, no sólo en el plano nacional sino también en el ámbito de la justicia global y la radicalización de la democracia.

La política de liberación es atravesada transversalmente por un planteamiento ético que cruza el mundo de la y lo político: las acciones, las instituciones y los principios. La obra de Dussel se crea dentro y responde a la polémica con intelectuales contemporáneos dentro de las ciencias sociales y las humanidades. Moreno (2011), lo plantea así: "La complejidad de lo que [Dussel] llama « el campo político », siguiendo a Bourdieu, le obliga a discutir contra el pragmatismo estratégico y decisionista de la filosofía política conservadora (como Carl Schmitt, que privilegia el momento de las acciones) ; contra el legalismo kantiano liberal (como Habermas, que privilegia el ámbito jurídico de las instituciones); y contra el principalismo voluntarista de tipo anarquista (como Antonio Negri o John Holloway, que privilegian el necesario pero insuficiente ámbito de los principios).”

Dussel trata de una manera amplia y novedosa, lo que él reconoce como los tres principios normativos implícitos de la política, los cuales han sido expuestos de manera formalista por algunos o negados por la mayoría de los filósofos políticos contemporáneos. Se trata de tres momentos normativos implícitos en toda sociedad histórica y política, que a su vez incorporan los principios éticos (Moreno, 2011): "la obediencia al principio material de verdad práctica como deber del querer vivir de una comunidad, conforme a un principio político de fraternidad (subsunción del principio 
ético-material de la vida); la obediencia al principio formal de igualdad en la participación discursiva de las tomas de decisiones políticas que afectan a la vida de la comunidad, conforme a un principio democrático o de legitimidad institucional (subsunción del principio ético-formal del discurso); la obediencia al principio de factibilidad como libertad en la aplicación de las posibilidades ecológicas, económicas, técnicas, etc. para la consecución de preservar y desarrollar la vida en comunidad, conforme a un principio político a la vez instrumental y estratégico (subsunción del principio ético de factibilidad)"

Enrique Dussel, problematiza a profundidad diversos campos que conforman aristas de su compleja obra; fractales que abren la visión hacia el interminable trabajo intelectual de uno de los más grandes filósofos en la historia del pensamiento crítico. Destacaremos seis diversos campos, aunque no exhaustivos de su obra, en los que se puede constatar la estrecha relación entre filosofía y política de liberación.

\section{1.- Entre Las Casas, Suárez y Vitoria; de la teología política a la modernidad colonial(izada)}

De acuerdo con Moreno (2011) "es interesante destacar la importancia que Dussel atribuye al siglo XVI portugués y español, una etapa intelectual que vivió el «Yo conquisto» de Hernán Cortés cien años antes de que Descartes, alumno de jesuitas españoles en La Flèche, proclamara el famoso «Yo pienso»." La escolástica española del siglo XVI, dirime el primer debate moderno en torno de la justificación de la conquista contra los indígenas sin alma (como hizo Ginés de Sepúlveda) o su defensa como alteridad radical (como hizo Bartolomé de las Casas) o la definición del pueblo como recipiendario de la soberanía, hasta entonces detentada, sin posible reclamo alguno, por la monarquía y el papa católico (como lo discutieron Francisco Suárez y Francisco de Vitoria, quienes le dieron protagonismo al pueblo en su derecho público -más allá del jus gens- y quienes dieron origen al derecho internacional, aunque estuviese centrado en el Estado nacional moderno).

Las Casas representaría, 300 años antes que Kant, la primera crítica del presente (Moreno, 2011): “Con esto España quedaría redefinida como el primer Estado 
«moderno», y América Latina, desde la conquista, sería el primer territorio colonial de la indicada Modernidad. Moderna, entonces, en tanto que es la «otra cara» bárbara que la Modernidad necesita para su definición."

Mario Ruiz Sotelo3, plantea que “Dussel observa en Las Casas un profeta no en la conocida idea de observador del futuro, sino por poder percibir el sentido profundo del presente ("el auténtico sentido de la palabra profecía", Dussel, 1977), el fundamento no visto por el común de sus contemporáneos, y que él habría podido percibir dada una especial capacidad para entender la realidad de su tiempo, que esencialmente es también la de nuestro tiempo, dado que el sistema que denunció no puede presumirse desmantelado." Además, para Mora (2009) Las Casas es reivindicado como precursor de uno de los movimientos latinoamericanos a los cuales se refiere el pensamiento decolonial, como lo es la teología de la liberación. Las Casas, no es ajeno a la reflexión sobre las condiciones de negación de la alteridad, el uso de la violencia y el espacio ofrecido a los excluidos del sistema.

Esa colonialidad del poder en su prolongación actual, se observa en el campo de las relaciones entre iglesias y estados, entre religiosidad, espiritualidad y política, donde se anudan la filosofía, la teología y la política de liberación, que se entrelazan en la obra de Dussel. En sus planteamientos, existe la problemática del pueblo como sujeto de la historia, emergida desde la conquista de América, y la peculiar apuesta teórico práctica de la teología de la liberación, cuya opción preferencial por los pobres implica también una apuesta política que busca empoderarles. Leonardo Boff (2018), comprende la antirealidad de la pobreza, con la finalidad de distanciarse de la realidad como determinante e inamovible, lo cual requiere de cierta precisión respecto del rol eficaz activo del "reino de los pobres". Ve tres comprensiones diferentes de pobre que están presentes todavía hoy en el debate. "La primera, tradicional, entiende al pobre como aquel que no tiene. No tiene medios de vida, no tiene renta suficiente, no tiene casa, en una palabra: no tiene bienes. Sobrevive en el desempleo, o en el subempleo, y con salario bajo [una segunda visión] progresista, ha descubierto ya el potencial de los pobres y ha percibido ya que ese potencial no es utilizado. Por la educación y la profesionalización el pobre viene a ser calificado y potenciado; [la tercera visión, con la que coincide Boff] es la liberadora,

\footnotetext{
${ }^{3}$ Cfr. Ruiz Sotelo, Mario: “Bartolomé de las Casas y la filosofía de la liberación”, de próxima aparición en un libro en homenaje a Enrique Dussel, que publicará la Universidad de Guadalajara.
} 
que afirma: los pobres sí tienen potencialidades, y no sólo para engrosar la fuerza de trabajo y reforzar el sistema, sino principalmente para transformarlo en sus mecanismos y en su lógica."

En su apuesta política, concluye Boff "Los pobres, concientizados, organizados por sí mismos y articulados con otros aliados, pueden ser constructores de otro tipo de sociedad. Pueden no sólo proyectar, sino poner en marcha la construcción de una democracia participativa, económica y ecológico-social. La universalización y la plenitud de esta democracia sin fin se llama socialismo. Esta perspectiva no es ni asistencialista ni progresista. Es verdaderamente liberadora, porque hace del oprimido el principal sujeto de su liberación y el forjador de un proyecto alternativo de sociedad."

\section{El análisis desde la exterioridad, entre Lévinas, Ricoeur y Heidegger}

Desde sus orígenes, Dussel incursiona en la contemporaneidad del pensamiento y sus indisolubles vínculos con la acción-realidad. Por lo cual se puede ubicar a este gran pensador en un doble sentido de actualidad: en la búsqueda auténtica de la relación entre saber y poder, desde el momento en que hace y define su obra particular; $y$, además, en la pertinencia del conjunto de su obra respecto de la ética política que corresponde al presente, desde un horizonte liberador ${ }^{4}$.

El grupo inicial que animó la filosofía de la liberación, contó con una generación de filósofos jóvenes, entre los que se encontraban Enrique Dussel, Arturo Roig, Horacio Cerutti Guldberg, Juan Carlos Scannone, Alberto Parisí, Daniel Guillot, Mario Casalla, entre otros. Los unen las tendencias contra el autoritarismo que se fragua en la Argentina de finales de los años 70 e inicios de los 80, pero más que una reflexión para la acción acotada a un espacio nacional, y no obstante cierta heterogeneidad de enfoques teóricos y praxicos, la naciente filosofía de la liberación, amplía su visión hacia una América Latina unida en la diversidad.

\footnotetext{
${ }^{4}$ Ver el trabajo, "La Filosofía de la Liberación de Enrique Dussel de los años 70. Un sistema de análisis desde la exterioridad", de Federico Ledesma Zaldívar, en el libro homenaje a Enrique Dussel que será publicado por la Universidad de Guadalajara.
} 
La obra dusseliana, dialoga con la teoría de la dependencia y sus críticos, con la visión liberadora de la educación formal y no formal, con la emergente sociología crítica, como es el caso de Orlando Fals Borda (2008), cuya obra coincide en la necesidad de producir un conocimiento nuevo, crítico y que contribuyera a la modificación de la realidad en términos de mayor justicia social. Desde el pensamiento crítico de Fals Borda se converje en la búsqueda de una vía propia de acción, pero también otra ciencia y otra cultura, gracias a la formación de "una ciencia nueva, subversiva y rebelde, comprometida con la reconstrucción social necesaria, autónoma frente a aquella que hemos aprendido en otras latitudes y que es la que hasta ahora ha fijado las reglas del juego científico, determinando temas y dándoles prioridades, acumulando selectivamente los conceptos..."

En la convergencia de pensamientos críticos, se trataba de una creación a partir de la realidad propia, un saber que trastocara el orden, un saber comprometido con una reconstrucción social. De acuerdo con Ledezma, "Las influencias dominantes de esa [primera] etapa fueron Paul Ricoeur, que proveyó a Dussel del concepto de núcleo ético mítico para analizar las culturas, y Martin Heidegger, desde quien empezó su esfuerzo de una ética de la liberación. [En una segunda etapa, se registra] la influencia del filósofo lituano, Emmanuel Lévinas.

El núcleo ético mítico de Paul Ricoeur, influye en la filosofía de la liberación, pues de acuerdo con Mora (2009) “la construcción del 'mito' de la modernidad se da para Dussel, cuando dicha emancipación es reivindicada e impuesta por medios irracionales a un Otro al cual se considera 'culpable' de su estado de 'inmadurez intelectual', por lo tanto, incapaz de emanciparse por sí mismo". No es una ontología anclada en la definición del ser, sino en un paso previo a que el ser pueda ser pensado, pues ese pensar implica ya una posibilidad realizada de un sujeto que ya es, en cambio es Dussel, con Lévinas, quien va a comenzar ahora desde el sujeto que no es (Martin Heidegger), cuyo ser está negado (Ledezma).

En su obra: Ética de la Liberación Latinoamericana (Dussel, 1973), examina las formas de dominación concreta. Lévinas, está en la experiencia originaria de la Filosofía de la Liberación pues descubre el «hecho» masivo de la dominación, del constituirse de una subjetividad como «señor» de otra subjetividad, en el plano mundial (desde el 
comienzo de la expansión europea en 1492: hecho constitutivo originario de la «Modernidad») Centro-Periferia; en el plano nacional (élites-masas, burguesía nacional clase obrera y pueblo); en el plano erótico (varón-mujer); en el plano pedagógico (cultura imperial, elitaria, versus cultura periférica, popular, etc.); en el plano religioso (el fetichismo en todos los niveles); en el nivel racial (la discriminación de las razas noblancas), etc. "Esta 'experiencia originaria' -vivida por todo latinoamericano aun en las aulas universitarias europeas de filosofía-, quedaba mejor indicada en la categoría de Autrui (otra persona como Otro), que como pauper...." (Dussel, 1998, p. 20, citado por Ledezma). Pero, Dussel va más allá de Lévinas, pues el otro no es un concepto multívoco, sino dialécticamente relacionado con el nosotros. Un principio fundamental para comprender la totalidad inmersa en la filosofía y la política, que es una liberación de todas y todos y no de una sola de sus partes: el otro.

De la totalidad a la liberación, supone el cambio de paradigma de la ontología a la alteridad. Por ello, cabe la distinción entre la fenomenología, que se ocupa de lo que aparece y cómo aparece desde el horizonte del mundo, el sistema, el ser. De la epifanía, que en cambio es "la revelación del oprimido, del pobre, del otro, que nunca es pura apariencia ni mero fenómeno, sino que guarda siempre una exterioridad metafísica. El que se revela es trascendente al sistema, pone continuamente en cuestión lo dado; la epifanía es el comienzo de la liberación real." (Dussel, 2011: 45)

En el filósofo de la liberación, se destaca el salto del pensar ontológico, es decir del pensar basado en el fenómeno, desde lo que se ve porque nuestros marcos nos lo permiten, al pensar desde lo que no se ve, de lo que escapa a la fenomenología y la ontología. Dussel propone iniciar con seis niveles de reflexión (Ledezma, cursivas mías):

a) proximidad: se trata del encuentro con el otro, del encuentro con el mundo, y como de esos dos encuentros debe surgir la revelación;

b) totalidad: porque el ser humano nace dentro de un mundo que está dentro de unas definiciones ya dadas, con las que va a tener que romper;

c) mediaciones [partes funcionales de la totalidad que nos permiten la aproximación. Es el ámbito de las cosas, de la proxemia, del acercamiento a los entes.];

d) exterioridad, que es el ir más allá de las definiciones del mundo, de las normas que ordenan las cosas dentro del sistema, lo que queda fuera del deber ser, la meta-física; 
e) alienación, que es cuando empieza la confrontación para hacer un pensamiento liberador. En la alienación el otro es visto como enemigo (momento teórico de la totalidad) y una vez que ha sido visto como enemigo, hay que aniquilarlo (momento práctico de la totalidad), aniquilar la diferencia, para guardar el orden, después se subsume la exterioridad dentro de la totalidad, es decir que se le da una definición que no desafíe el orden;

f) liberación [La liberación entonces tiene que romper con la ontología, con el orden de cosas presentes (en muy diversos ámbitos)]."

\section{La filosofía (siempre contemporánea) de la liberación, de Enrique Dussel}

La agenda actual que propone la obra dusseliana, combate "la existencia de comunidades no libres, sometidas, consideradas como inferiores por otra cultura que mediante múltiples mecanismos y aparatos de control colonizan, oprimen, reprimen o explotan a la cultura que considera inferior, todo ello bajo el amparo de eufemismos como progreso, asistencia, civilización, equidad, incorporación y toda una batería semántica que acompaña el proceso con el propósito de encubrirlo." (Salinas Paz s/f)

De acuerdo con Salinas Paz (s/f), los 5 puntos fundacionales de la Filosofía de la Liberación, son:

1. Renuncia a la modernidad filosófica

2. Anuncia el pensar desde la exterioridad

3. Establece la doble tarea del pensar desde la exterioridad, tarea destructivoconstructiva, de la filosofía que oculta la opresión y de la que se vincula a la praxis de liberación.

4. De la ontología a la política como posición primera, y

5. La Filosofía Latinoamericana como única posible entre nosotros.

Filosofía, Teología, Política de Liberación, parten del pensamiento crítico, como el arte de formular las preguntas y problemáticas no pensadas desde la perspectiva de la opresión, iluminando espacios encubiertos por el discurso de las filosofías que tienden a 
legitimar tal opresión. Ahí se sitúa una apuesta por una epistemología del sur (Dussel, 2015, p. 20), contra la imposición por parte del pensamiento del centro, que encubre la dominación como un resultado natural de su presupuesta superioridad cultural. De este proceso resulta una hegemonía que es combinación de coerción y también, no hay que olvidarlo, de una aceptación de esa dominación; una clave de lectura en torno de Gramsci. Como lo hace ver Salinas Paz, Dussel también tiene presente la categoría de epistemicidio, desde una lectura que hace de Boaventura de Sousa Santos ${ }^{5}$.

Salinas Paz (s/f), hace una profunda y erudita problematización sobre las polémicas de Dussel con Richard Rorty, en cuanto al giro lingüístico en la filosofía, respecto del papel central de la razón y con Otto Apel, en lo que hace al giro pragmático. Dos autores que son muy importantes en la propuesta de la filosofía de la liberación, pues está pendiente dar continuidad al giro descolonizador epistemológico: "tomar conciencia crítica desde el mundo poscolonial del eurocentrismo, como lugar de expresión del discurso habitus generalizado del pensador" (Dussel, 2015, p. 333, citado por Salinas Paz). Es notable el dialogo de Dussel con autores contemporáneos de las ciencias sociales, como Pierre Bourdieu, y Michel Foucault, en lo que es la genealogía de la liberación, donde se muestra que el saber, no necesariamente sujeto a la razón occidental, como lo plantea Rorty, no es el mero discurso, como fuente pragmática como lo plantea Apel, que da un estatus de superioridad al lenguaje centrado en la racionalidad anglo europea.

Refiriéndose a la genealogía de la liberación, Salinaz Paz abre la perspectiva "hacia nuevos espacios y nuevas preguntas que iluminan lo encubierto, por lo menos momentáneamente, para ampliar la perspectiva, establecer nuevas agendas de discusión donde los no escuchados, aquellos que su voz se ha transformado en un ruido para el sistema, aquellos que desde la opresión, represión, exclusión y condición subalterna puedan ser escuchados." Lo que interesa en esta genealogía, es la lucha por la legitimidad entre unos y otros, tomando en cuenta que se usa y expulsa a los excluidos en medio de un proceso de dominación, en donde el que dirige tiene el consenso del

\footnotetext{
5 "La identificación de las condiciones epistemológicas permite mostrar la vastísima destrucción de conocimientos propios de los pueblos causada por el colonialismo europeo - lo que llamo epistemicidio - y, por otro lado, el hecho de que el fin del colonialismo político no significó el fin del colonialismo en las mentalidades y subjetividades, en la cultura y en la epistemología y que por el contrario continuó reproduciéndose de modo endógeno" (SOUSA SANTOS, 2010),
} 
grupo solo mediante un proceso de simulación, cuyo pensamiento opresor se presenta como objetivo, científico y abocado al progreso de "todos". Sin embargo, "la propia simulación delata que el consenso real está perdido, se presenta simulado por lo que parece que solo le queda al grupo de élite mecanismos de simulación y apariencia."

En el ensayo sobre México, que presenta Salinas Paz (s/f) en un libro próximo a publicarse por la Universidad de Guadalajara, están contenidas estas categorías relativas al nacimiento y potencialidad de la filosofía y la política de la liberación. México es una suerte de holograma desafiante a los procesos de liberación: un poder oligárquico que reúne los resabios del racismo, la discriminación y la injusticia, que se enmarcan en el Sistema Mundo de la Modernidad-Colonialidad; un gobierno que bebe de la simulación y que extiende el pensamiento único, que denega cualquier altrnativa; un Estado cuyas instituciones atentan contra la memoria y la resistencia; un tejido social asediado permanentemente por la imposición de un modelo de acumulación depredador y basado sobre el despojo. La violencia, es totalitaria y supresora de derechos; Salinas Paz lo plantea así: “Todos unidos orgánica y recíprocamente en la violencia. No pensamiento crítico, no transformación, solo reproducción de lo mismo, el imperio del pensamiento único, violento y relampagueantemente homicida, globalmente genocida. Sinfonía de la muerte en espera del inesperado turno propio."

Citando a Foucault: el trabajo "De la utopía del progreso a la heterotopía de la resistencia”, de Salinas Paz, hace ver que: "Ese mundo en operación viene legitimado por un espacio cultural que hace coexistir en armónica complicidad tanto nuestro sistema de democracia representativa como nuestro sistema de violencia.", con lo cual se adentra en los vínculos entre lenguajes, saberes y liberación. Su apuesta es por un saber genealógico de y para la liberación, inserto en una hermenéutica que vincula discursos con instituciones en términos de prácticas discursivas y no discursivas. Este enfoque, de clara inspiración dusseliana, "da cuenta de modos eficientes de uso del poder, manejo de masas, gobernabilidad en términos neoliberales. La arqueología es la descripción de un discurso-objeto. Este saber, carente de autor, disciplina, corriente, configura un saber interdisciplinario y complejo [que] configura sujetos sociales que tienen que habérselas con instituciones, (poder) y consigo mismos (ética)." 


\section{Eurocentrismo y ética liberadora en Enrique Dussel}

Para Arturo Chavolla (s/f)6 , la crítica de Dussel al eurocentrismo es un esfuerzo por ser contemporáneo, que apuesta por la eticidad, como búsqueda de proyecto civilizatorio liberador, por ello, entra en un debate entre la globalización y la exclusión (su obra de 1998), en la cual regsitra un doble movimiento en el que se encuentra apresada la Periferia mundial: "por una parte, la pretendida modernización dentro de la globalización formal del capital (en su nivel financiero principalmente: «capital ficticio» nos dice Marx); pero, por otra parte, la exclusión material y discursivo formal creciente de las víctimas de ese pretendido proceso civilizador".

Para la crítica del eurocentrismo, "se necesitó tiempo para poder alcanzar un grado de complejidad civilizatorio suficiente que permitiera a la «ética» y a la «moral» lograr grados mas abstractos de universalidad y llegar así a niveles evolutivos crecientes de criticidad." En distintas partes de su obra, Dussel presenta la evolución histórica del «sistema interregional», en cuatro estadios, lo cual comporta una tesis central: "las «eticidades» de la humanidad se fueron generando en torno y desde un sistema asiáticoafricano-mediterráneo, que desde el siglo xv es, por primera vez, un «sistema mundial»."

Al proceso generado por Dussel para tratar al «sistema-mundo», podemos añadir la concepción de la modernidad / colonialidad, como una superación de los tres estadios del «sistema interregional» que lo preceden (por «región» se entiende una alta cultura o sistema civilizatorio). Según la interpretación de Dussel (1998), hay cuatro estadios:

“a) En un primer estadio, el «sistema interregional» fue solo la estructura de las relaciones de la región egipcio-mesopotámica. La India, China y Amerindia no se conectaban directamente todavía.

“b) En un segundo estadio, el «sistema interregional» creció abarcando desde el Mediterráneo y el norte del África hasta el Medio Oriente, la India y la China a través de las estepas euroasiáticas (las regiones influenciadas por los «indoeuropeos»), hegemonizando

\footnotetext{
${ }^{6}$ Chavolla Flores, Arturo (s/f) Eurocentrismo y la obra de Enrique Dussel, de próxima publicación por la Universidad de Guadalajara. Desde una amplia lectura, que toma en cuenta las obras de Dussel que mejor expresan la crítica al pensamiento eurocéntrico, Arturo Chavolla (s/f) tiene en cuenta especialmente sus obras: "Hipótesis para el estudio de Latinoamérica en la Historia Universal" (1966), "1492, el encubrimiento del otro" (1992), "Historia de la filosofía y filosofía de la liberación" (1994), "Europa, modernidad y eurocentrismo" (2003), "Política de la liberación. Historia mundial y crítica" (2007).
} 
o teniendo por centro-conector el mundo persa o el helenístico de los Seléucidas o de los Ptolomeos.

“c) En un tercer estadio, el mundo cristiano, el bizantino primero y musulmán después, reemplazan al helenístico y juegan el rol de bisagra en todo el sistema (desde la China y la India al Mediterráneo).

“d) En un cuarto estadio, la Europa periférica reemplaza al mundo musulmán-turco y constituye el primer «sistema-mundo» propiamente dicho, colocando a Amerindia como su primera periferia."

Esta Ética de la Liberación pretende situarse explícitamente en el horizonte de este «sistema-mundo» moderno, el cuarto estadio, (Dussel, 1998) "teniendo en consideración no solo el «centro» (como lo ha hecho exclusivamente la filosofía moderna desde Descartes hasta Habermas, y que por ello ha tenido una visión parcial, provinciana, regional del acontecer ético histórico), sino también desde su «periferia» (y por ello se obtiene una visión planetaria del acontecer humano)”.

De acuerdo con Chavolla (s/f) "En el fondo se está contra el colonialismo teórico de la filosofía política tal como se practica en América Latina, por lo que se aboga por tomar en serio el «giro descolonizador» en el que está empeñada desde hace decenios la filosofía de la liberación, insistiendo en la necesidad de partir de nuevas bases en nuestra reflexión, que no pueden ser meramente imitativas o de comentadores autorizados de la filosofía política europeo-norteamericana...”

Concebir la periferia desde la noción de la colonialidad del poder, desarrollada por Aníbal Quijano, permite analizar que la expansión imperial de Europa a partir del siglo XVI constituye un patrón de poder global que se caracteriza por la imposición de una clasificación étnica y racial a la población del mundo. Esta imposición "opera en cada uno de los planos, ámbitos y dimensiones, materiales y subjetivas, de la existencia social cotidiana y a escala societal" (Quijano, citado en Mora, 2009).

Dussel afirma, de acuerdo con Mora (2009) que la lógica que ha impuesto la Modernidad está fundamentada en una serie de presupuestos. Hay un "mito fundador" que se puede resumir así: "la civilización europea se autocomprende como más moderna, por lo tanto se encuentra en la obligación moral de 'civilizar' a los demás pueblos y culturas. Frente a esta 'modernización', el Otro (el 'bárbaro') puede ofrecer 
resistencia, como cuando los 'indios' no permiten la libre circulación de los españoles en sus territorios. La resistencia debe de ser vencida, aunque sea mediante la fuerza, para hacer imperar la lógica superior. Lógica que va en beneficio de los mismos bárbaros." Un camino que conduce a la justificación de la guerra, el gran debate que detona la configuración del sistema mundo moderno.

\section{El pensamiento geopolítico y la modernidad en la política de la liberación de Dussel}

José Guadalupe Gandarilla (s/f) ${ }^{7}$ sugiere que Dussel toma en serio la relación entre espacio y tiempo, entre geografía e historia, pues se trata de una formulación filosófica que "ha puesto especial atención en la dimensión espacial, y en las configuraciones en que ese elemento de las relaciones sociales (y de las prácticas a través de las que se restituyen los referentes sólidos y profundos de la cultura), asume expresiones en las que su politización (el modo en el que juega un determinado papel para la constitución política del actuar concreto de los sujetos) va revelando contenidos multidimensionales, según sea el modo cómo incida su lógica en ciertos campos de la actividad humana (material, ecológico, cultural), o por su intermedio se vean involucradas ciertas capas de realidad (la de la conciencia, la corporalidad, la presencia del otro) en la configuración misma de las formas de subjetividad que la expresión de la totalización de la vida material va evidenciando en un trayecto de largo tiempo; para el tema que nos interesa, la de sus variantes moderna o, pretendidamente, transmoderna." (subrayado mío).

La espacialidad politizada en un horizonte liberador, es una característica que está en las raíces del conocimiento, del saber y del poder -de la filosofía, la política y la teología-, que son constitutivas de la epistemología dusseliana. Como se vio antes, los cuatro estadios de la historia de la larga duración que se proponen en su obra, en los que más de tres mil quinientos años dieron pie a tres sistemas regionales, los cuales desembocaron en el cuarto estadio, el primero en el que emerge un sistema mundo de la

\footnotetext{
${ }^{7}$ Está por publicarse su trabajo: Geopolítica, modernidad y política de la liberación, en un libro en homenaje a Enrique Dussel, por la Universidad de Guadalajara.
} 
modernidad / colonialidad. Desde ahí, surge un mundo con pretensiones de universalidad, que se estructuró bajo la lógica de la conquista, la invasión, la ocupación, la colonización, "el cercamiento". Gandarilla evidencia que en la obra de Dussel hay una compleja relación interdisciplinaria respecto de las ciencias sociales y en particular con la corriente crítica de la geopolítica y su enfoque decolonial.

Para la geopolítica crítica no son extrañas las relaciones de poder que se constituyen en la historia de las relaciones sociales desde la filosofía de la praxis, como no lo son tampoco los campos de la actividad humana localizados e imbricados en la naturaleza como su base material. Una totalización de la vida material que está animada y que es transformada por intersubjetividades en las que se tejen mitos y discursos culturales sistémicos, que son fundadores de comunidades políticas y sociales -vale decir socioespaciales, como las ciudades, los estados, las formas de sociabilidad territorializadas-, las cuales son nutridas por imaginarios sustentados por actores sociales diversos. La capacidad heurística convocada por esa geopolítica crítica, potencia el rol transformador del horizonte liberador. Con la modernidad / colonialidad del poder, se abrieron y diversificaron los procesos de dominación, pero con ella se revitaliza el pensamiento crítico que evidencia, denuncia y enuncia los efectos de los diversos formatos de dominación, la identificación de las víctimas y también de sus contrapoderes e imaginarios civilizatorios otros.

Pensar el mundo como base material natural de la totalidad económica, política, social y cultural, estructurada por el poder de dominación, implica el reconocimiento de la jerarquía entre dominante y dominado en su expresión de centro y periferia, así como reconocer las diferencias y desigualdades geográficas - a la manera como las concibe David Harvey-, digamos entre norte y sur -el Sur Global, que plantea Giovanni Arrighi-, y en una escala que vincula la esfera local de la experiencia, la conciencia, la corporalidad, el reconocimiento de la otredad -dicho con Foucault y su microfísica del poder-, con la escala global de la realidad material totalizada, pasando por otras escalas geopolíticas como la región, el Estado nacional, los espacios supranacionales.

A esas orientaciones epistemológicas se refiere Gandarilla, cuando resalta la originalidad del pensamiento social crítico latinoamericano y caribeño. El pensamiento de la CEPAL, desde la perspectiva del estructuralismo de Raul Prebisch, o la teoría de la 
dependencia de Fernando Henrique Cardoso y Enzo Faletto, y sus innumerables críticos (Theotonio dos Santos+, Ruy Mauro Marini+, Vania Bambirra+, Agustín Cueva+, René Zavaleta+, Daniel Camacho...) los neomarxistas con sus críticas a la economía política internacional, como Atilio Borón, Emir Sader, y una gran diversidad de enfoques gramscianos $^{8}$, maoístas, trotskistas. Aníbal Quijano, Walter Mignolo, Edgardo Lander, hacen una geopolítica del conocimiento, crítica al eurocentrismo que domina en el mainframe académico, a través de los estudios decoloniales. El geógrafo brasileño Milton Santos que ofrece una perspectiva afín a la de Dussel, en la que se anuncia un vínculo ya indeleble entre la economía política internacional y la ecología política (Enrique Leff), en sus vertientes críticas.

Como resultado de un enfoque interdisciplinario, la geopolítica crítica comparte con Dussel el reconocimiento de la creación de contra-espacios para comprender la configuración transversal del Sistema mundo y su anclaje en actores que parten desde perspectivas epistemológicas, ontológicas y prácticas diferentes a las euro-anglocéntricas, no sólo en América Latina, sino en la dinámica del Sur Global. Frente al llamado Post-extractivismo, entendido como rasgo de época por Arturo Escobar (2012), se argumenta que en la búsqueda de alternativas en América Latina se están confrontando dos proyectos complementarios pero contradictorios: uno trata de llevar adelante modernizaciones alternativas, mediante estrategias de desarrollo antineoliberal y post-capitalista. Otro, busca la transición del modelo de sociedad, mediante saberes y prácticas decoloniales, pluriversales y que también buscan trascender o superar al neoliberalismo. Para decirlo en palabras de Gandarilla, "coexisten diversas espacialidades críticas, cuyos proyectos ensayan formas sociales y políticas de liberación otras, junto con la existencia de 'comunes translocales', que las expresiones diversas de una 'multitud global' persiste en defender puesto que logra visibilizarlos en tanto que instancias (locales) en que obran tales atributos (de ser bienes comunes que afectan planetariamente o que generan incidencias de tal proyección)...”

\footnotetext{
${ }^{8}$ Gandarilla refiere en este libro: "una veta para el desarrollo de un marxismo creativo la documenta lo ocurrido en el caso del intelectual sardo Antonio Gramsci quien, en nuestra región, alcanzó enunciaciones vernáculas que se anudan a planteos de gran riqueza polisémica (por ejemplo, la noción de "filosofía de la praxis", que Adolfo Sánchez Vázquez, desde México, rastrea y promueve con enjundia) o a usos polimorfos (hegemonía, revolución pasiva y, sobre todo, lo nacional-popular) desde su incursión temprana (por vía de los esfuerzos de los argentinos Agosti, y sus discípulos, Portantiero y Aricó), pero que se mantuvieron hasta mediados de los años ochenta, etapa en la que internacionalmente comenzó la vulgata a propósito de "la crisis del marxismo"'
} 
Emergen dentro de este sistema mundo de la modernidad/colonialidad, dos discursos que se mueven dentro de las tensiones entre espacio y tiempo: el discurso de la conciencia utópica, que se abre al futuro como imaginado, y el de la dimensión del porvenir, que fue acaparado por la ideología del progreso. Sin embargo, la manera como se comprime o dilata la relación espacio-tiempo, nos dice Gandarilla: "se da en el horizonte efectivo (moderno colonial) y no solo figurado (utópico) del nuevo momento del sistema-mundo; quizá sea por esa razón que, el geógrafo italiano Franco Farinelli caracterice a la modernidad no a la heideggeriana, como 'etapa de la imagen del mundo' sino como resultado de la imposición 'de la representación geográfica del mundo': la localización de las cosas sobre el mapa geográfico no las toma a éstas per se sino en su posibilidad de transformarlas en mercancías..." La hegemonía del mercado como horizonte de realidad, perturba ambos discursos que debate la modernidad. De aquí que la concepción de trasmodernidad dusseliana presente su potencial transformador frente a utopías no situadas en el campo geopolítico, además de la demoledora crítica a la ideología del progreso como vocación del proyecto moderno.

\section{Transmodernidad: alternativas que superen la modernidad-colonialidad del Sistema Mundo}

Gandarilla ofrece una interesante polémica con el filósofo Paik Nak-chung, de Corea del Sur, que se refieren a las herramientas conceptuales que interpelan a la modernidad en su totalidad, como lo hacen: Enrique Dussel con transmodernidad, Immanuel Wallerstein con capitalismo histórico y Aníbal Quijano con colonialidad del poder. El pensador sudcoreano está cerca de la idea transmoderna de Dussel, pero para el pensador asiático, la formulación de Dussel "no captó adecuadamente el doble aspecto de adaptación y superación". No obstante, Gandarilla afirma que la noción de transmodernidad no se limita a "superar" la Modernidad sin pronunciarse por "las exigencias de avanzar "a través de ella", además, oponer el "superar" a la noción de "avanzar a través de" puede llevar a "cierta simplificación”. El riesgo sería mediatizar el concepto de transmodernidad dusseliano, con sus respectivas consecuencias políticas, 
pues la praxis liberadora no consiste en un doble proyecto de adaptarse a la modernidad y superarla simultáneamente.

En la obra de Dussel, se plantean polémicas con lo que pudiera considerarse como visiones evolucionistas lineales y adaptativas del proyecto moderno, y la forma en que se presenta la modernidad como imperativo, en el llamado a "ser absolutamente moderno" de Arthur Rimbaud, citado por Paik, pero "no a cumplir plenamente con la modernidad capitalista". De acuerdo con Gandarilla, lo que Enrique Dussel plantea en su concepto de transmodernidad, es que en toda crítica a la Modernidad se ha de partir de "ámbitos o momentos que guardan exterioridad con respecto a la totalidad de la modernidad. Esa exterioridad negada y despreciada son las culturas en aquello que la modernidad no pudo dominar" (Dussel, 2014). Puede concluirse que lejos de instaurarse las pretensiones universalistas del imaginario moderno, como lo expresa la idea de Bruno Latour de que nunca fuimos modernos, la transmodernidad se constituye sobre la base de universalismos situados en tiempos y espacios heterogéneos, dentro de los cuales además coexisten resistencias y contrapoderes que comparten universalmente esperanzas liberadoras de la opresión, del racismo y de toda forma de discriminación.

En la discusión sobre el concepto de transmodernidad Solorio y Ortiz (s/f) ${ }^{9}$, se deslindan frente al pensamiento único que quiere recuperar la globalización como máxima expresión de lo universal, y también se formulan críticas pertinentes de cara al imaginario postmoderno. Para estos autores, "Se trata de un devenir trazado desde ciertas categorías conceptuales que dejan ver una historia definida e interpretada desde un polo geográfico y cultural que oculta el profundo sentido multicultural de la humanidad, lo cual debe seguir siendo discutido en diversos ámbitos para problematizar esa historia universal que se sigue enseñando en Occidente".

Destacan aquí dos campos problemáticos, ambos asociados con la diversidad cultural: uno tiene que ver con las políticas de reconocimiento, relativas al derecho a la diferencia -como aceptación de la otredad-, enunciadas como políticas multiculturales o interculturales; otro, se refiere a la narrativa de la historia universal que se enseña y su interfaz con la historia vivida desde la pluriversidad de los actores o sujetos "que hacen"

\footnotetext{
${ }^{9}$ Solorio Rojas, Ana Silvia, y Juan Diego Ortiz Acosta (s/f) "La Transmodernidad como posibilidad de realización de otro mundo. Una mirada desde el pensamiento de Enrique Dussel", próximo a publicarse por la Universidad de Guadalajara.
} 
la historia. Está en juego el carácter y sentido del cambio o transformación de las sociedades, la manera en que se transitan periodos o épocas de la humanidad y lo que hace singular al Sistema Mundo Moderno, como portador del espíritu universal poseedor de Una razón, de Una idea de progreso, de Un camino del "desarrollo", pero que esconde sus estrategias y capacidades para dominar a otros pueblos. Dicen estos autores: "Dejando a las demás culturas sin el derecho a trazar su propio destino por una presunta inmadurez en su geografía y su cultura, quedando así sometidos a la hegemonía europea que se erigió como el 'centro y fin de la historia mundial, al decir de Hegel." (Solorio y Ortiz)

En aras de formular su concepto de transmodernidad, Dussel critica la persistencia del eurocentrismo. Un "primer" eurocentrismo, por aquella interpretación que se funda en la superioridad probada de Europa a partir de sus orígenes griegos, luego concretizados en la implantación de la subjetividad moderna, la cual se apoyó sobre la Ilustración francesa e inglesa y el Romanticismo alemán. Este primer eurocentrismo, tiene su expresión política alrededor de las revoluciones estadounidense y francesa, con la proyección del imaginario democrático, y toma su perfil socioeconómico con la revolución industrial manufacturera destacada en la Inglaterra del siglo XVIII. El "segundo" eurocentrismo, presenta una plataforma de superación de esa modernidad universalista homogeneizante, pues es en torno de la propuesta del Sistema Mundo Moderno, de Immanuel Wallerstein, que Dussel enfatizará la violencia negadora de los derechos de los pueblos otros, de sus saberes y de sus particularidades culturales. Un deslinde teórico que también operó una crítica del marxismo que fue copado por los paradigmas de la razón y el progreso propios de la modernidad.

Solorio y Ortiz (s/f) resumen la manera como esa doble crítica al eurocentrismo fundamenta el imaginario transmoderno dusseliano: "Así como la conquista del continente americano dio origen a la globalidad, a la economía-mundo, al sistemamundo, la relación dialéctica entre el centro del poder y la periferia tejió lo que conocemos como Modernidad, pues como bien expresa Dussel, 'no hay modernidad sin modernizado'. Desde esta óptica que reconoce la existencia de los pueblos negados en el proceso modernizador, es que pueden ser superados el 'primer' y 'segundo' eurocentrismo, para así poder aproximarnos a un proyecto verdaderamente mundial [de liberación], un proyecto transmoderno". 
"La Transmodernidad, es la inclusión de la alteridad negada, esa exterioridad capaz de reconocer su positividad y su capacidad creativa, que ha permanecido oculta tras el telón moderno". En esta cita de Dussel, está implícita la posibilidad de crear no una sino varias alternativas a la modernidad, particularmente en su versión liberal, pues aquí si importa que hay una o mejor dicho varias búsquedas, las cuales emergen desde el ensayo, desde el todavía no, desde la prefiguración de otra realidad, distinta y antagónica frente a la impostura modernista. Tampoco la postmodernidad puede ir más allá de la modernidad que critica, como lo señalan Solorio y Ortiz, "en tanto que sus discursos [postmodernos] parten de Europa, no cuestionan su centralidad y son incapaces de imaginar que las culturas excluidas por el proceso moderno (desde 1492) puedan desarrollar de forma autónoma una etapa posterior a la culminación de la Modernidad europea."

Son adecuadas las palabras de Moreno (2011) para finalizar este trabajo, pues la larga obra de Enrique Dussel, ya desde los años 60 consagrada a la construcción de una nueva ontología transmoderna asume la existencia de las víctimas excluidas por el discurso filosófico y, sobre todo, por la práctica histórica y sus instituciones. "En este proyecto teórico de liberación que abarca más de 60 obras, Dussel ha puesto énfasis especial en una reinterpretación ética de Marx y, con ella, la construcción de una ética de la liberación". Indudablemente que la obra de Dussel en torno de la filosofía y la política de la liberación, siempre será un estímulo heurístico para adentrarse en su producción intelectual y así ofrecer todo un campo de alternativas frente a la modernidad opresora, excluyente, depredadora, patriarcal y colonizadora del poder, del pensamiento, que evacua cualquier alternativa que amenace su hegemonía.

Referencias

BOFF, Leonardo (2018) "Dom Pedro Casaldáliga cumple 90 años: pobreza y liberación", Publicado en América Latina en movimiento (https://www.alainet.org). Consultado en: https://www.alainet.org/es/articulo/191097

DUSSEL, Enrique (1973) Para una ética de la liberación latinoamericana, Tomo I, Ediciones Siglo XXI, Buenos Aires. 
DUSSEL, Enrique (1977) Religión, Sociológica Conceptos, Ed. EDICOL, México.

DUSSEL, Enrique (1998) Ética de la liberación en la edad de la globalización y la exclusión, Editorial Trotta, Madrid.

DUSSEL, Enrique (1998) Ética de la Liberación en la Edad de la Globalización y de la Exclusión, Ed. Trotta, España.

DUSSEL, Enrique (2011) Filosofía de la Liberación, FCE, México.

DUSSEL, Enrique (2014) 16 tesis de economía política: interpretación filosófica, México, Siglo XXI editores.

DUSSEL, Enrique (2014) 16 tesis de economía política: interpretación filosófica, México, Siglo XXI editores.

DUSSEL, Enrique (2015) Filosofías del Sur. Descolonización y Transmodernidad Edición: Editorial Akal, México.

ESCOBAR, Arturo (2012) “ ¿Transformaciones y/o transiciones? Post-extractivismo y pluriverso, América Latina en Movimiento (on line), 22 de marzo, recuperado en: https://www.alainet.org/es/active/53567

FALS BORDA, Orlando. Orígenes universales y retos actuales de la IAP (investigación acción participativa) Peripecias № 110 - 20 de agosto de 2008, disponible en: http://www.peripecias.com/mundo/598FalsBordaOrigenesRetosIAP.html

MORA, Luis Adrián (2009). "Francisco de Vitoria y Bartolomé de Las Casas desde la perspectiva del pensamiento decolonial”, en Revista Ixchel, Volumen I.

MORENO LAX, Alejandro (2011) “«La Política de la liberación» de Enrique Dussel”, en El correo de la diáspora latinoamericaine, enero, consultado en:

http://www.elcorreo.eu.org/La-Politica-de-la-liberacion-de-Enrique-

Dussel?lang=fr\#nh6-5

SOUSA SANTOS, Boaventura de (2010), Descolonizar el saber, reinventar el poder, Ediciones TRILSE, Uruguay. 